\title{
NOVOS REGISTROS E UMA ESPÉCIE NOVA DE TRICHORHINA BUDDE-LUND (ISOPODA, ONISCIDEA, PLATYARTHRIDAE) DO SUL DO BRASIL
}

\author{
Paula Beatriz de Araujo 1, 2 \\ Ludwig Buckup 1,3
}

\begin{abstract}
NFW RECORDS AND A NFW SPFCIES OF TRICHORHINA BUDDE-LUND (ISO-

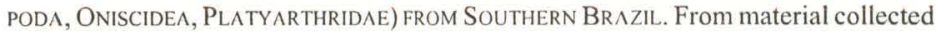
in Santa Catarina and Rio Grande do Sul States (Brazil) two new records of Trichorhi$n a$ are presented (T. argentina Vandel, 1963 and T. tomentosa (Budde-Lund, 1893) as

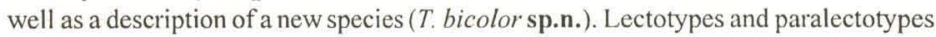
of $T$. argentina are designated. A key for the species in the study area is also included. KEY WORDS. Isopoda, Oniscidea, Trichorhina, new species, Brazil
\end{abstract}

O gênero Trichorhina, com aproximadamente 60 espécies descritas (SoUZA-KURY 1991) tem, até o presente, o registro de apenas duas espécies para o sul do Brasil. ANDERSSON (1960) descreveu, a partir de material proveniente de Nova Teutônia (Santa Catarina), T. brasiliensis. ARAUJO \& BUCKUP (1994), analisando material coletado em várias localidades do sul do Brasil, descreveram T. acuta.

Os resultados apresentados neste trabalho foram obtidos a partir do estudo de amostras coletadas nos Estados de Santa Catarina e Rio Grande do Sul. Das três espécies de Trichorhina identificadas, duas constituem registros novos e outra, uma espécie ainda não descrita. Optou-se por incluir uma chave para todas as espécies do gênero que ocorrem na área de estudo, considerando-se, portanto, aquelas já registradas pelos pesquisdores citados acima.

Trabalhando com o material-tipo de T. argentina, verificou-se que a espécie descrita por VANDEL (1963) estava representada por síntipos. Considerando a breve descrição e a não designação do holótipo, optou-se por uma redescrição da espécie bem como proceder na designação do lectótipo e paralectótipos. Para este estudo, solicitou-se empréstimo ao Muséum National d'Histoire Naturelle Paris (MNHN), na pessoa do Dr. H. Dalens, curador da coleção de Alfred Vandel. Constatou-se, inclusive, que o número de exemplares examinados, existentes na coleção, foi de dois machos e uma fêmea e não um macho e duas fềmeas conforme mencionado pelo autor.

1) Departamento de Zoologia, Instituto de Biociências, Universidade Federal do Rio Grande do Sul. Avenida Paulo Gama 40, 90040-060 Porto Alegre, Rio Grande do Sul, Brasil.

2) Escola Técnica, Universidade Federal do Rio Grande do Sul. Rua Ramiro Barcelos 2777 , 90053-007 Porto Alegre, Rio Grande do Sul, Brasil.

3) Bolsista do CNPq. 
O material coletado encontra-se depositado no Setor de Crustáceos Superiores do Departamento de Zoologia da Universidade Federal do Rio Grande do Sul (UFRGS).

Chave para as espécies de Trichorhina encontradas no sul do Brasil

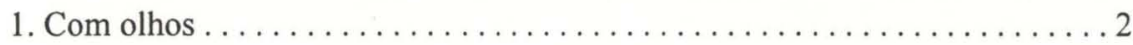

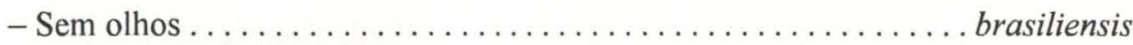

2. Olhos com mais de um omatídio; corpo pigmentado; um nódulo lateral em cada lado do pereionito VII . . . . . . . . . . . . . . . . . . 3

- Olhos com um omatídio; corpo despigmentado; dois nódulos laterais em cada lado

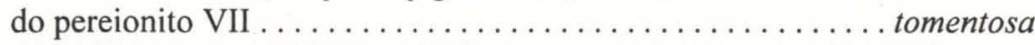

3. Telso com ápice obtuso; olhos com cinco a seis omatídios $\ldots \ldots \ldots \ldots \ldots 4$

- Telso com ápice formando uma ponta; olhos com quatro omatídios . . . . . . acuta

4. Tegumento uniformemente pigmentado; cerdas escamosas como na figura 2; exito da maxílula com dentes fendidos . . . . . . . . . . . . argentina

_. "Pleon" despigmentado; cerdas escamosas como na figura 27; exito da maxílula com dentes inteiros $\ldots \ldots \ldots \ldots \ldots \ldots \ldots \ldots \ldots \ldots$ bicolor sp.n.

\section{Trichorhina argentina Vandel, 1963}

Figs 1-15, 41

Trichorhina argentina Vandel, 1963: 73, fig. 6.

Lectótipo macho. ARgentinA, Buenos Aires: Punta Lara (lamaçal próximo a La Plata, fragmento de floresta tropical), 03-V-1959 (MNHN PLA1.). Paralectótipos: fêmea (MNHN PLA2.) e macho (MNHN PLA3.3-4950.1; PLA3.3-4950.2; PLA3.3-4950.3; PLA3.3-4950.4 -lâminas) com os mesmos dados do lectótipo.

Material adicional. BRASIL, Santa Catarina: Joaçaba (pátio de residência, sob pedras e folhas), 19-I-1991, 2 machos, 1 fêmea (UFRGS 01517); Sombrio (sob madeira tijolos e lixo), 15-V-1991, 1 macho, 2 fêmeas (UFRGS 01518). Rio Grande do Sul: Camobi (Universidade Federal de Santa Maria, sob folhas e lixo), 05-II1991, 1 fêmea, 3 fêmeas ovígeras (UFRGS 01519); Eldorado do Sul (Fazenda Minuano, em moita de gramínea, próximo às raízes), 02-IV-1991, 2 machos, 2 fêmeas, 5 fêmeas ovígeras (UFRGS 01520); Eldorado do Sul, idem, 23-VII-1991, 5 machos, 4 fêmeas, 1 fêmea ovígera (UFRGS 01521); Caçapava do Sul (sob madeira), 12-I-1991, 1 fêmea (UFRGS 01522); Camaquã (terreno baldio, próximo ao muro), 23-III-1991, 2 machos, 1 fêmea, 2 fêmeas ovígeras (UFRGS 01523); Rio Grande (Taim, Estação Ecológica do Taim, sob folhas), 17-VI-1991, 1 macho, 1 fêmea ovígera (UFRGS 01524).

Diagnose. Corpo pigmentado, olhos com 5-6 omatídios negros, 1-3 poros glandulares, antênula com 7-8 estetascos, exito da maxílula com 4+4 dentes (dois fendidos), pereionitos I-VII com um nódulo lateral de base simples.

Redescrição. Medidas (maior espécime); macho: comprimento 2,98mm, largura, 1,25mm; fêmea: comprimento 4,0mm, largura 1,75mm. 

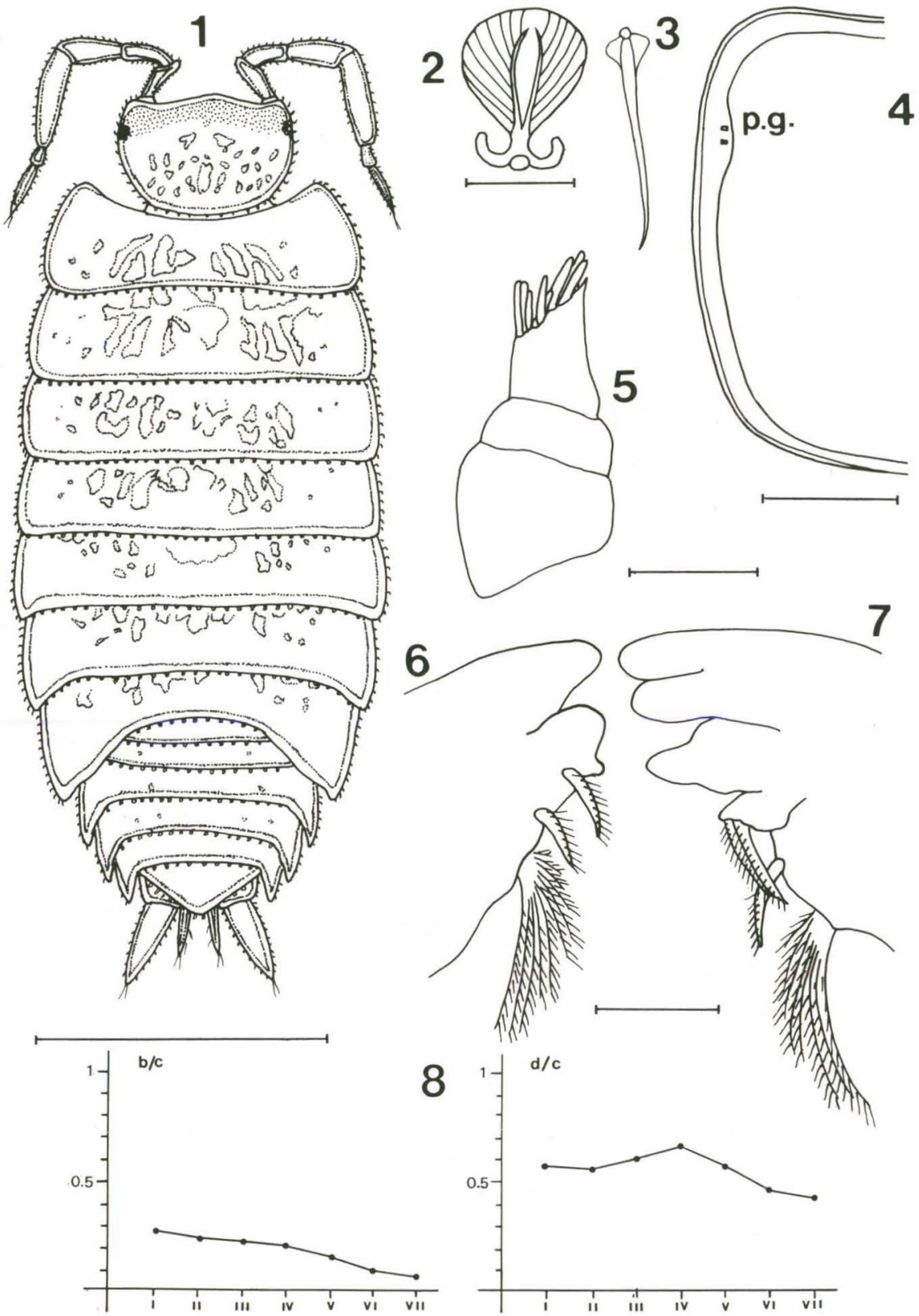

Figs 1-8. Trichorhina argentina, macho. (1) Vista dorsal; (2) cerda escamosa; (3) nódulo lateral; (4) pereionito 1, p.g.=poros glandulares; (5) antênula; (6) mandibula direita; (7) mandíbula esquerda. (8) posição dos nódulos laterais com relação às margens dos pereionitos I-VII: b/c (margem posterior), d/c (margem lateral). Escalas: Figs 1, $4=1 \mathrm{~mm}$; Figs $2-3=0,025 \mathrm{~mm}$; Figs $5-7=0,05 \mathrm{~mm}$. 


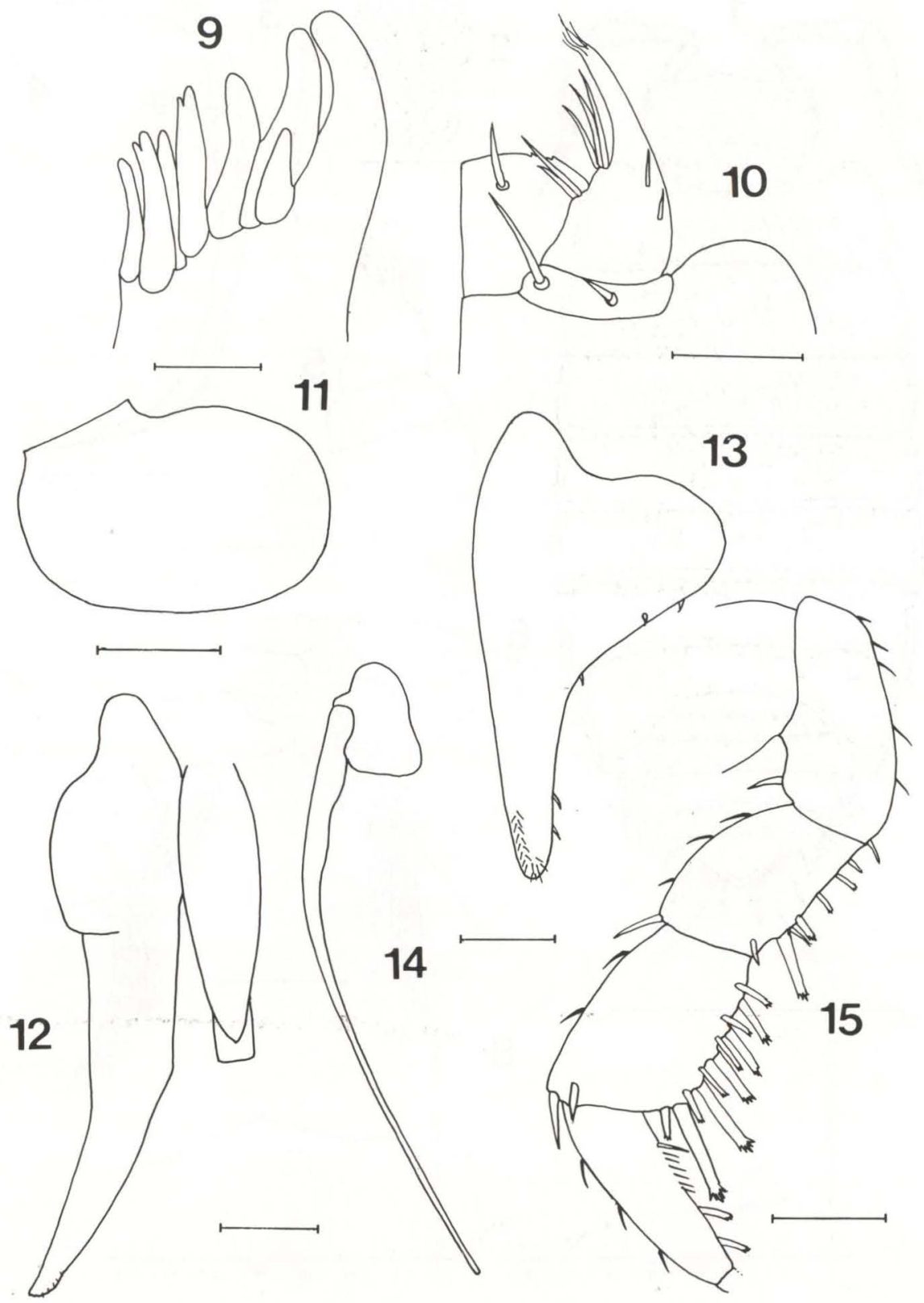

Figs 9-15. Trichorhina argentina, macho. (9) Exito da maxilula; (10) maxilipodo; (11) exópodo do pleópodo $1 ;$ (12) endópodo do pleópodo 1 ; (13) exópodo do pleópodo 2 ; (14) endópodo do pleópodo 2; (15) pereiópodo 1 (paralectótipo macho). Escalas: Figs. 9-10 =0,05mm; Figs $11-15=0,1 \mathrm{~mm}$. 
Coloração. Pigmento violáceo uniformemente distribuído no dorso, podendo apresentar um tom marrom claro, com pequenas manchas esbranquiçadas. Lobos da cabeça escuros. Urópodos geralmente despigmentados. Olhos negros.

Caracteres gerais. Cabeça, quando em posição normal, parcialmente envolvida pelas projeções ântero-laterais do pereionito I; olhos com cinco a seis omatídios. "Pleon" estreitando-se gradualmente a partir do limite posterior do "pereion" (Fig. 1). Telso triangular com os lados retos e ápice obtuso.

Tegumento. Superfície lisa, com placas semi-circulares e coberta por cerdas escamosas estriadas em forma de leque (Fig. 2). Antena com placas semelhantes, tricornes, cerdas escamosas e cerda apical no artículo distal do flagelo. Nódulos laterais com base simples (Fig. 3). Posição dos nódulos laterais ilustrada na figura 8. Com um a três poros glandulares (Fig. 4).

Apêndices. Artículo distal da antênula com sete a oito estetascos (Fig. 5). Segundo artículo do flagelo antenal inteiro. Mandíbulas com mais de sete penicílios no processo molar; direita (Fig. 6) com 1+1 penicílios, esquerda (Fig. 7) com 1+2 penicílios. Exito da maxílula com $4+4$ dentes (dois fendidos) (Fig. 9). Endito do maxilípodo (Fig. 10) com dois dentículos na borda superior e com a margem interna reta. Urópodos com endópodos que alcançam a metade do comprimento dos exópodos.

Dimorfismo sexual: Pereiópodo 1 do macho (Fig. 15) com espinhos simples. Pereiópodo 7 sem dimorfismo aparente. Pleópodo 1 do macho com exópodo de contorno oval, podendo apresentar até duas pequenas cerdas na margem externa (Fig. 11); endópodo (Fig. 12) com a metade distal voltada para o lado externo e ápice com diminutos pêlos. Pleópodo 2 do macho com exópodo subtriangular e margem proximal sinuosa (Fig. 13); endópodo (Fig. 14) afilado no terço distal.

Observações: espécie com registro anterior somente para a localidade-tipo; amplia-se o conhecimento da distribuição geográfica para o sul do Brasil (Fig. 41).

\section{Trichorhina tomentosa (Budde-Lund, 1893)}

Figs 16-25, 41

Alloniscus tomentosus Budde-Lund, 1893:126

Sinonímia: consultar SoUZı-KURY (1991)

Material examinado. Brasil, Santa Catarina: Blumenau (pátio de residência), 17-V-1991, 2 fềmeas, 1 fềmea ovígera (UFRGS 01995); Blumenau (mata ao redor de residência), 17-V-1991, 1 fềmea (UFRGS 01996); Pouso Redondo (amontoado de folhas varridas com frutas apodrecidas), 18-V-1991, 3 fêmeas, 3 fềmeas ovígeras (UFRGS 01998); Tubarão (pátio de residência), 15-V-1991, 2 jovens, 20 fêmeas, 4 fêmeas ovígeras (UFRGS 01999); Sombrio (pátio de residência, sob madeira), 15-V-1991, 1 fềmea (UFRGS 02000). Rio Grande do Sul: Fontoura Xavier (pátio de residência), 01-II-1991, 1 fêmea (UFRGS 02001); Porto Alegre (Fundação Zoobotânica do Rio Grande do Sul, sob madeira), 27-IX-1992, 1 fêmea (UFRGS 02002). 


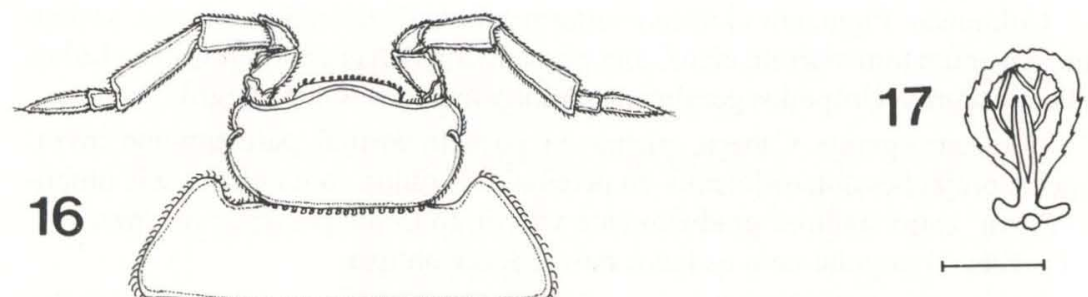

18
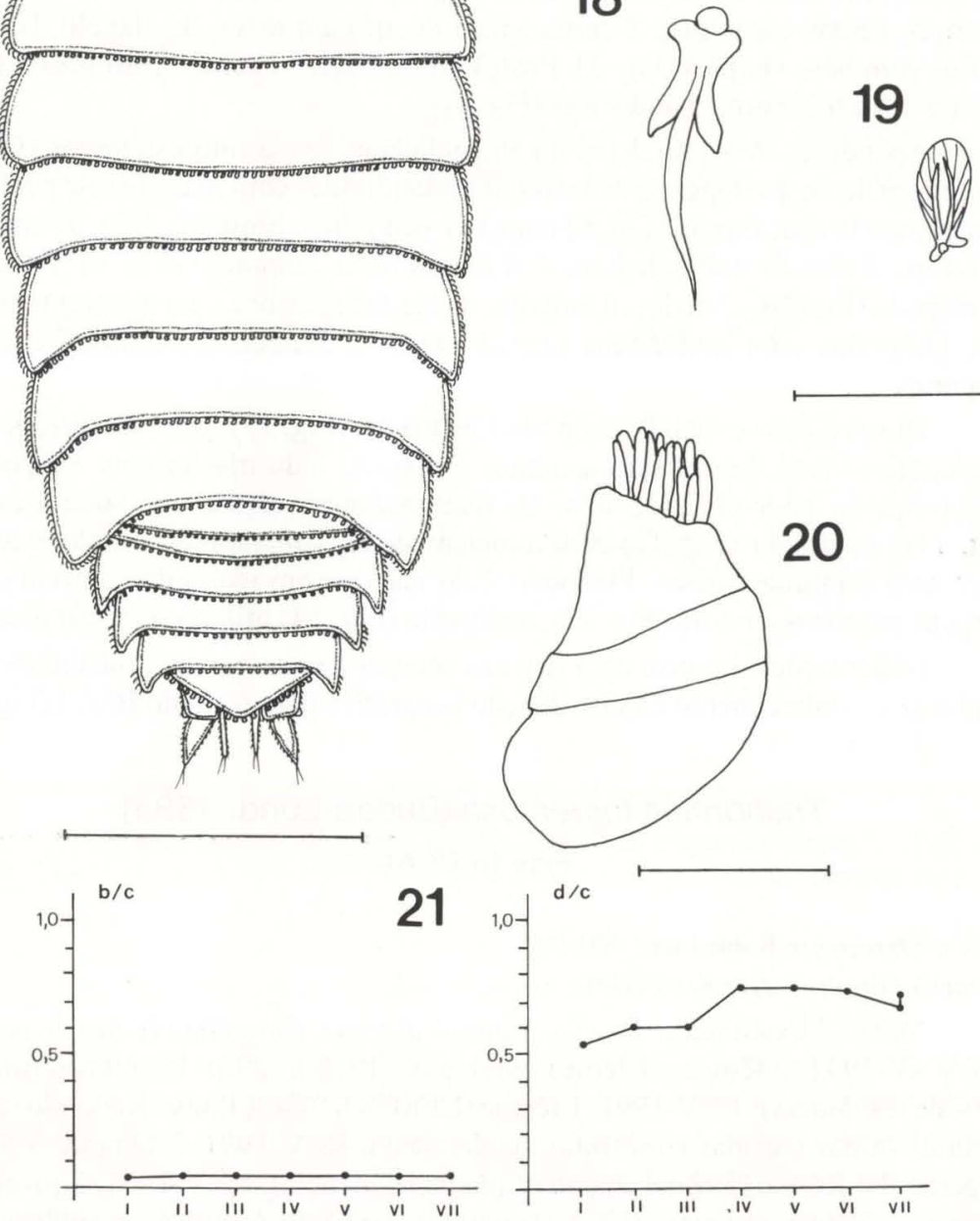

Figs 16-21. Trichorhina tomentosa, fêmea. (16) Vista dorsal; $(17,19)$ cerdas escamosas; (18) nódulo lateral; (20) antênula; (21) posição dos nódulos laterais com relação às margens dos pereionitos I-VII: b/c (margem posterior), d/c (margem lateral). Escalas: Fig. 16=1 $\mathrm{mm}$; Figs $17-19=0,025 \mathrm{~mm}$; Fig. $20=0,05 \mathrm{~mm}$. 


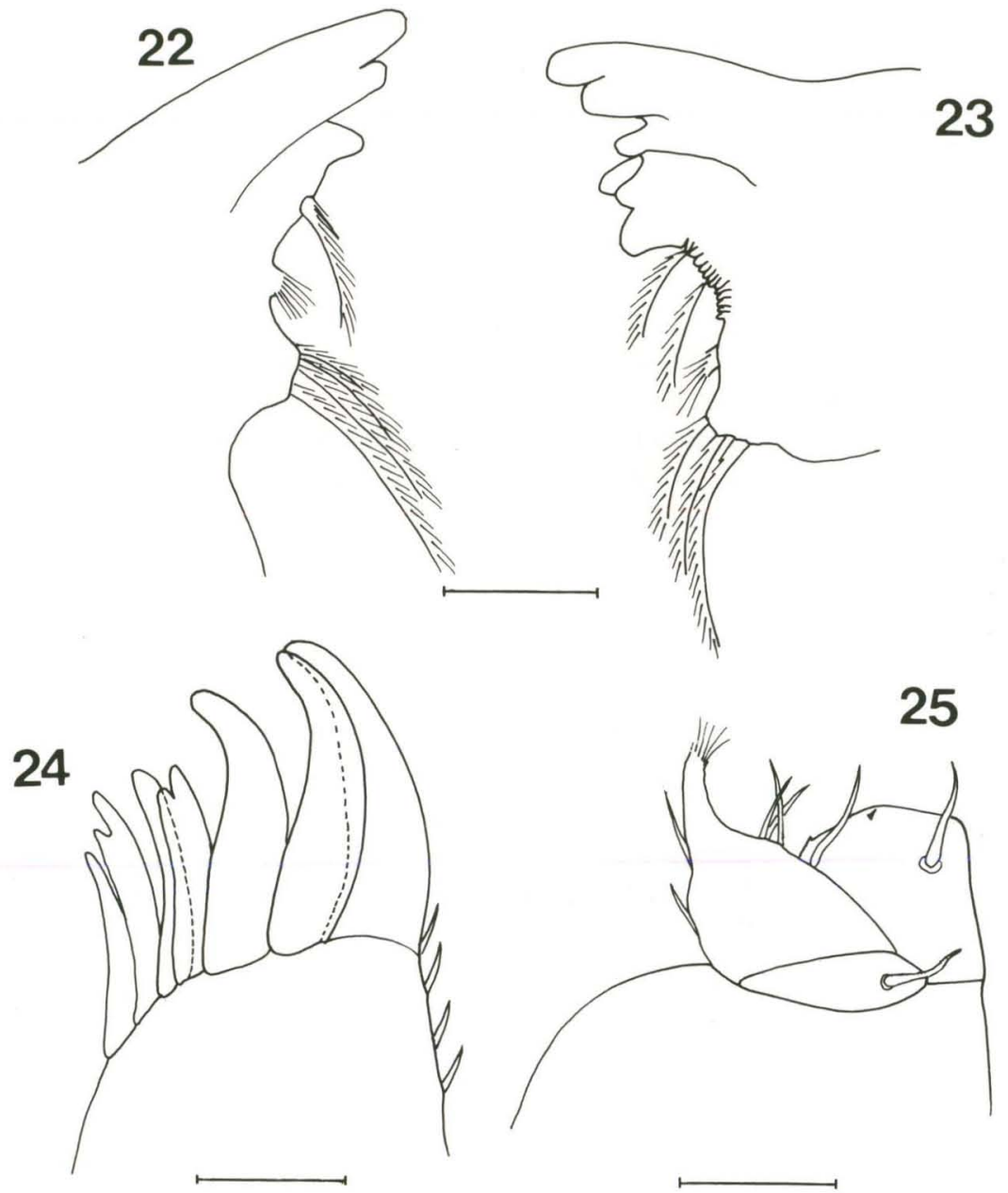

Figs 22-25. Trichorhina tomentosa, fêmea. (22) Mandibula direita; (23) mandibula esquerda; (24) exito da maxílula; (25) maxilipodo. Escalas: Figs 22, 23, 25=0,05mm; Fig. $24=0,025 \mathrm{~mm}$.

Descrição diagnóstica. Medidas (maior fêmea ovígera encontrada); comprimento $3,50 \mathrm{~mm}$, largura, $1,60 \mathrm{~mm}$. Corpo despigmentado, olhos castanhos ou levemente avermelhados, com um omatídio (Fig. 16). Superfície corporal lisa, com placas semi-circulares e cerdas escamosas (Figs 17, 19). Nódulos laterais que emergem de uma base com duas projeções laterais (Fig. 18); uma de cada lado nos pereionitos I-VI e duas de cada lado no pereionito VII; posição das coordenadas b/c e d/c nos gráficos (Fig. 21). Artículo distal da antênula com 12 estetascos (Fig. 20). Segundo artículo do flagelo antenal inteiro. Mandíbula esquerda com uma fileira de bastonetes entre o processo molar e o incisor (Fig. 23); mandíbula direita sem bastonetes (Fig. 22). Exito da maxílula com 3+4 dentes (dois fendidos). Endito do maxilípodo com dois dentículos (um em posição mediana) (Fig. 25). Urópodos com endópodos que ultrapassam em comprimento a metade dos exópodos. 
Observações. Para T. tomentosa, uma espécie com registro em outras localidades brasileiras (Região Norte, Sudeste e Centro-Oeste, segundo SOUZA-KURY 1991), amplia-se o conhecimento da distribuição geográfica para a Região Sul (Fig. 41).

\section{Trichorhina bicolor sp.n.}

Figs $26-40,41$

Holótipo macho. BRasiL, Santa Catarina: Tubarão (28³0'S, $49^{\circ} 01^{\prime} \mathrm{W}$, fragmento de floresta, sob folhas), 15-V-1991 (UFRGS 02003H). Parátipos. BRASIL, Santa Catarina: São Bonifácio (pátio de residência, sob tijolos), 1 fêmea, 1 fêmea ovígera, 16-V-1991 (UFRGS 02004P); Pouso Redondo (pátio de residência, em amontoado de folhas varridas, com frutas apodrecidas), 1 fêmea, 18-V-1991 (UFRGS 02005P).

Diagnose. "Pereion" pigmentado, "pleon" despigmentado, olhos com seis omatídios negros, telso cobrindo apenas a porção proximal dos endópodos dos urópodos, antênula com cinco estetascos, exito da maxílula com $3+3$ dentes (nenhum fendido).

Descrição. Medidas - macho: comprimento $1,9 \mathrm{~mm}$, largura $0,75 \mathrm{~mm}$; fêmea (maior): comprimento $2,3 \mathrm{~mm}$, largura $0,9 \mathrm{~mm}$; fêmea ovígera: comprimento $2,9 \mathrm{~mm}$, largura $1,2 \mathrm{~mm}$.

Coloração. Pigmento amarelo e castanho pálido no "pereion" e região cefálica; "pleon" despigmentado (característica mais facilmente observável em material vivo ou conservado há pouco tempo); olhos negros:

Caracteres gerais. Bordas anteriores dos pereionitos atingem a altura dos olhos; lobos cefálicos laterais aparentes. Olhos com seis omatídios. Abdome estreitando-se gradualmente a partir do limite posterior do "pereion" (Fig. 26). Telso triangular, com as margens laterais suavemente côncavas e ápice obtuso, cobrindo apenas a porção proximal dos endópodos dos urópodos.

Tegumento. Superfície corporal lisa, com placas semi-circulares, coberta com cerdas escamosas estriadas alongadas (Fig. 27). Nódulos laterais com base simples (Fig. 28), um em cada lado dos pereionitos.

Apêndices. Artículo distal da antênula com cinco estetascos (Fig. 29). Antena sem crista ou quilha; segundo artículo do flagelo, inteiro. Mandíbulas (Figs 30-31) com 1+1 penicílios e três penicílios no processo molar. Exito da maxílula com $3+3$ dentes (nenhum fendido) (Fig. 32). Endito do maxilípodo com dois dentes na borda distal, sendo que esta apresenta contorno reto. Pereiópodos com placas semi-circulares.

Dimorfismo sexual. Pereiópodo 1 do macho (Fig. 38) com cerdas bifurcadas no mero e carpo; fêmeas sem este tipo de cerda (Fig. 39). Pereiópodo 7 do macho (Fig. 40) sem dimorfismo aparente. Pleópodo 1 do macho com exópodo apresentando extremidade distal alongada, alargada e com borda sinuosa (Fig. 34); endópodo com a borda lateral externa distal serrilhada (Fig. 35). Pleópodo 2 com exópodo subtriangular (Fig. 36); endópodo extremamente afilado no terço distal (Fig. 37). 

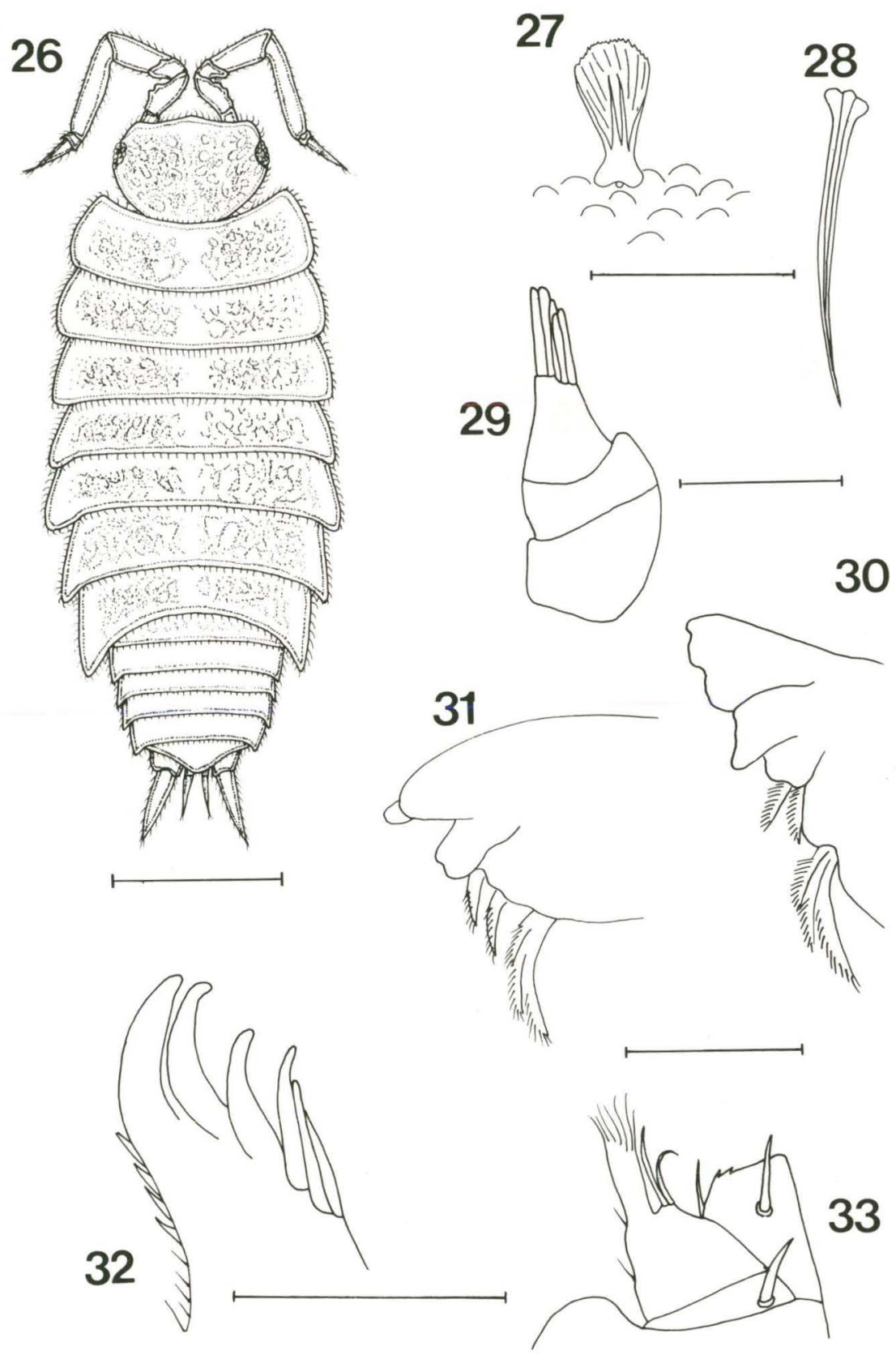

Figs 26-33. Trichorhina bicolor sp.n., holótipo macho. (26) Vista dorsal; (27) cerda escamosa; (28) nódulo lateral; (29) antênula; (30) mandibula esquerda; (31) mandibula direita; (32) exito da maxilula; (33) maxilipodo. Escalas: Fig. $26=0,5 \mathrm{~mm}$; Figs $27-33=0,05 \mathrm{~mm}$. 

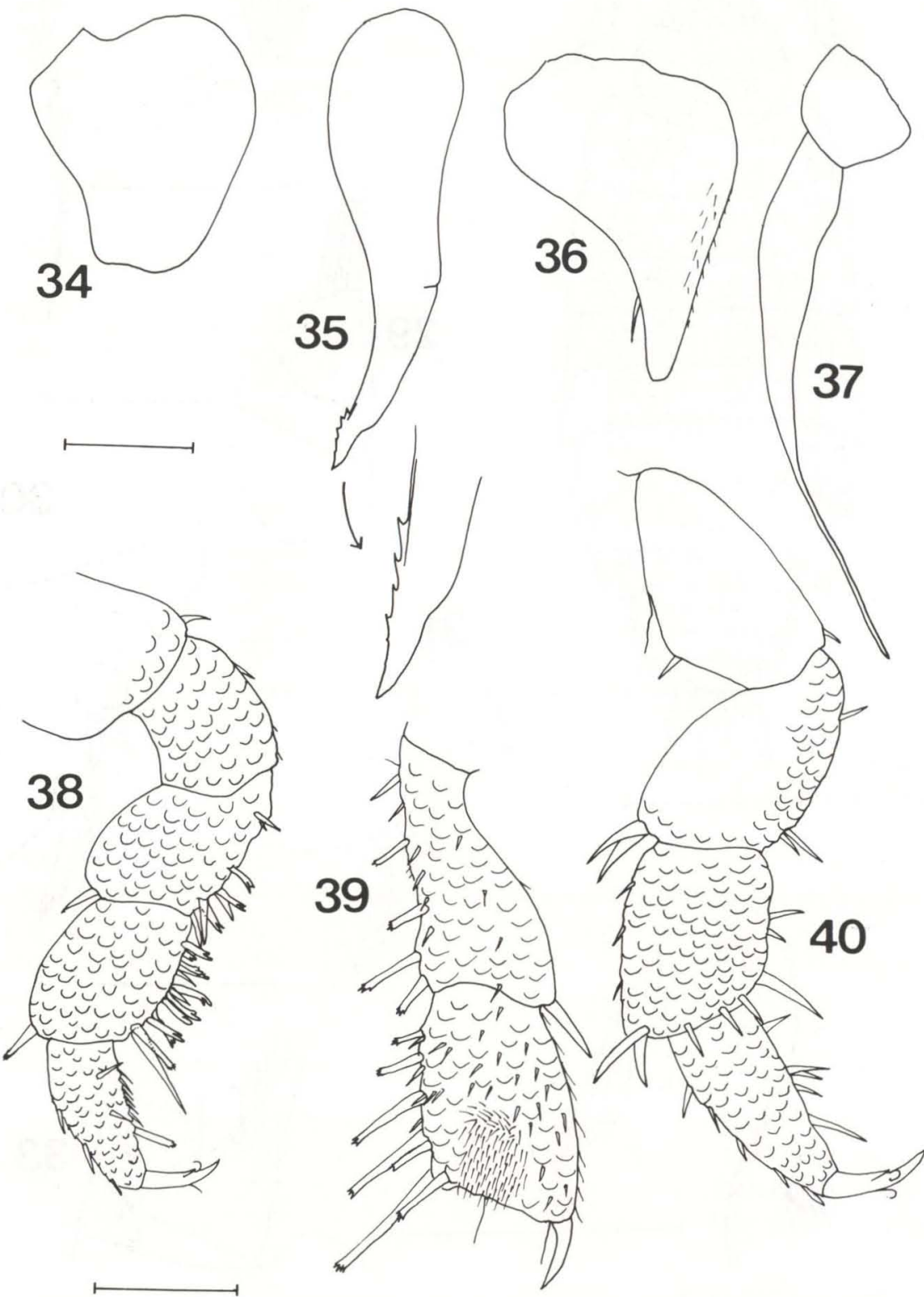

Figs 34-40. Trichorhina bicolor sp.n., macho. (34) Exópodo do pleópodo 1; (35) endópodo do pleópodo $1 ;$ (36) exópodo do pleópodo 2; (37) endópodo do pleópodo 2; (38) pereiópodo 1; (39) pereiópodo 1, fêmea; (40) pereiópodo 7, macho. Escalas: 0,1mm. 


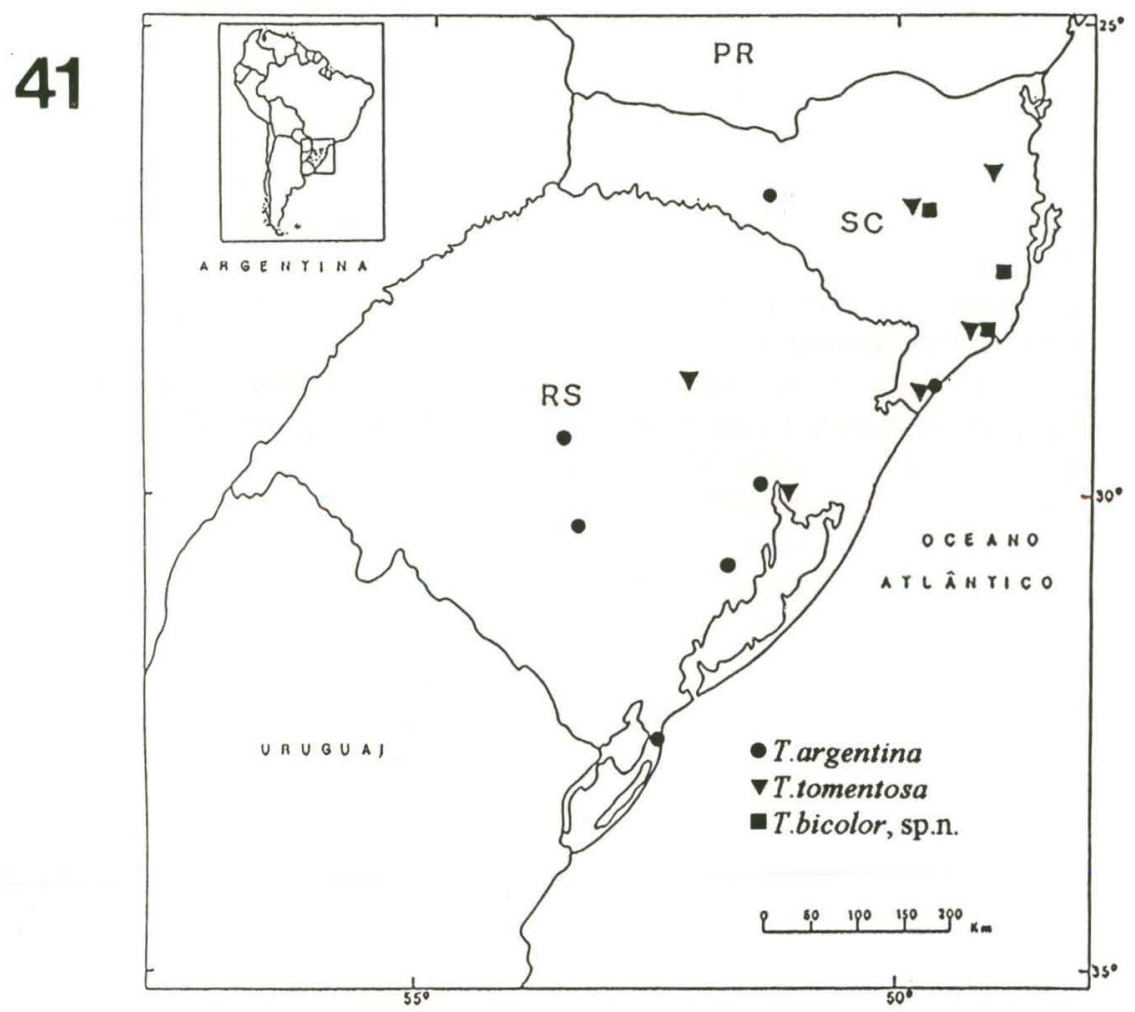

Fig. 41. Registros de ocorrência de Trichorhina argentina, $T$. tomentosa e $T$. bicolor sp.n. no sul do Brasil.

Etimologia. O adjetivo específico refere-se ao padrão de coloração: "pereion" pigmentado e "pleon" despigmentado.

Observações. Trichorhina bicolor diferencia-se das demais espécies do gênero que têm seis omatídios por apresentar: exito da maxílula com seis dentes inteiros (cinco dentes inteiros e um fendido em T. papillosa (Budde-Lund, 1893); nove dentes em T. australiensis Wahrberg, 1922; sete dentes em T. pallida Barnard, 1960; oito dentes em T. argentina), todos os omatídios pigmentados [só dois pigmentados em T. quisquiliarum (Budde-Lund, 1893)], antênula com cinco estetascos (nove em $T$. dobrogica Radu, 1960; sete a oito em T. argentina); por não apresentar: "botõezículos" como em T. albida Budde-Lund, 1908, sutura no segundo artículo do flagelo como em T. barbouri (Van Name, 1926) e relevos longitudinais no mesoepistoma como em T. gianellii Arcangeli, 1929.

AGRADECIMENTOS. Ao Dr. Marcos S. Tavares por intermediar o contato com o Dr. H.Dalens do Muséum National d'Histoire Naturelle Paris, a quem também agradecemos pelo empréstimo do material-tipo de T. argentina. Nossos agradecimentos à L.A. Souza-Kury por enviar espécimes de $T$. tomentosa, para fins comparativos. 


\section{REFERÊNCIAS BIBLIOGRÁFICAS}

ANDERSSON, A. 1960. South American terrestrial isopods in the collection of the

Swedish State Museum of Natural History. Ark. Zool. 12 (5-6): 537-570.

ARAUJO, P.B. \& L. BUCKUP. 1994. Nova espécie de Trichorhina Budde-Lund, 1908

(Crustacea, Isopoda, Platyarthridae) do sul do Brasil. Iheringia, Sér. Zool., 77 : 129-134.

BudDE-LuND, G. 1893. Landisopoden fra Venezuela, indsamelede af Dr. Fr.

Meinert. Ent. Meded. 4: 111-129.

SouZA-Kury, L.A. 1991. Sistemática das espécies brasileiras oceladas de

Trichorhina Budde-Lund, 1908 (Crustacea, Isopoda, Oniscidea). Tese de

Mestrado, não publicada, Museu Nacional, Universidade Federal do Rio de Janeiro, Rio de Janeiro, 125p.

VANDEL, A. 1963. Isopodes terrestres recueillis en Amèrique de. Sur par Claude

Delamare Debouteville, p.63-100. In: C. Delamare Debouteville \& E.H.

RAPOPORT (Eds). Biologie de l'Amerique Australe. Études sur la faune du sol. Paris, CNRS e CNICT, vol. 2.

Recebido em 02.I.1996; aceito em 28.XI.1996. 